\title{
A Study on Ethical Customer Management and Organizational Sustainability in Pharmaceutical Industry in Malaysia
}

\author{
Lee Yu Han, Lawrence Arokiasamy, and Joel Tham Kah Marn \\ Master of Business Administration, Business and Law Faculty, International University Malaya-Wales, 50480 Malaysia
}

\begin{abstract}
Pharmaceutical industry is not just a commercial business, their products are about life and death, and improving our life quality. This paper aims to study the ethical issues in customer management and how it contributes to organizational sustainability in Malaysia pharmaceutical industry. A quantitative research designed to collect primary data from questionnaire and secondary data from journal and articles focused on ethical customer management and pharmaceutical sustainability. The paper recognized 5 pillars; Direction, Posture, Organization, Behavior and Environment in DPOBE sustainability model and aligned them into ethical customer management in pharmaceutical which contribute positive impact towards organization sustainability in Malaysia. The findings of this paper serves as a guideline to pharmaceutical customer service agents in Malaysia SSC. It emphasizes the importance of ethical customer management and its impact to organization sustainability.
\end{abstract}

\section{INTRODUCTION}

\subsection{Introduction}

Table 1: 2014 Top 10 pharma companies by global sales

\begin{tabular}{|l|l|l|l|l|l|}
\hline$\#$ & Company & Origin & $2014(\mathbf{m})$ & $2013(\$ \mathrm{~m})$ & Growth (\%) \\
\hline 1 & Novartis & Switzerland & 47101 & 47468 & -1 \\
\hline 2 & Pfizer & United States & 45708 & 47878 & -5 \\
\hline 3 & Roche & Switzerland & 39120 & 39163 & 0 \\
\hline 4 & Sanofi & France & 36437 & 37124 & -2 \\
\hline 5 & Merck \& Co. & United States & 36042 & 37437 & -4 \\
\hline 6 & Johnson \& Johnson & United States & 32313 & 28125 & 15 \\
\hline 7 & GlaxoSmithKline & United Kingdom & 29580 & 33330 & -11 \\
\hline 8 & AstraZeneca & United Kingdom & 26095 & 25711 & 1 \\
\hline 9 & Gilead Sciences & United States & 24474 & 10804 & 127 \\
\hline 10 & Takeda & Japan & 20446 & 19158 & 7 \\
\hline & & Source Global Data $\mathbf{2 0 1 4}$ & & \\
\hline
\end{tabular}

Since the very first true antibiotic, penicillin was developed in 1940s; pharmaceutical industry has been developing rapidly to maintain a steady supply of lifesaving medications and improving life quality (Yeoh, 1994) (Landmarks,2017). According to PMLive and GlobalData, among the 20 top global sales pharmaceutical companies, majority are companies originated from United States and Europe (PMLive, 2017). As one of the most innovative and researchintensive industries in the United States, pharmaceutical firms are constantly facing pressures from the governments and stakeholders (Bunniran, McCaffrey, Bentley, \& Bouldin , 2009). From a molecule concept or idea discovery, to experiments, research \& development, clinical trials, to obtaining approval from FDA and finally marketing the new drugs to the public, it takes approximately 10 to 15 years (Pilon \& Elias, 2015). While there are other factors that affect a patent duration, the common term of a new patent is 20 years from the date on which the application for the patent was filed in the United States, based on data published on FDA website (United States Food \& Drug Administration, 2017). The cost to develop a new drug was estimated at $\$ 802$ million (Bunniran, McCaffrey, Bentley, \& Bouldin , 2009) in year 2009. However, the cost has increased enormously to approximately $\$ 2.6$ billion in 2015 (Pilon \& Elias, 2015). 
With expensive investment and long experiment duration needed on 1 medication, drug pricing is a global issue. In 2008, pharmaceutical expenditure in the European Union has recorded high at $€ 180$ billion (Kenneally \& Walshe, 2012). The figure is about $17 \%$ of EU countries' total expenditure on health, on average. There are particular concerns about the growth of pharmaceutical research cost in Ireland and the government is continuously looking for policies towards economic sustainability and welfare of their peoples.

Over the year, health expenditure in Asian countries has increased along with economic growth in countries like Thailand and Malaysia. The demand for quality health care in public and private sectors has also increased (Teerawattananon, Tangcharoensathien, Tantivess, \& Mills, 2003). Thailand national health expenditure in 1994 was $3.56 \%$ of GDP with $49 \%$ spent on public sector and $51 \%$ in private sector. In

World Health Organization (WHO) emphasized that continuous supply of medication to meet the needs of the present (Kenneally \& Valerie, 2012) is crucial for the health and wellbeing of human being. With new deceases discovered and evolved every now and then, development of new vaccines has to be carried out in a faster speed and more effectively. These is only possible when the pharmaceutical industry is sustainable; as a result of ethical management with integrity and compliance, high control in product and service quality (Farooq, Salam, Fayoll, Jaafar, 2018).

In order to maintain an efficient and standardized customer management, some large pharmaceutical companies have invested in inter-organizational shared service centres (SSC) to promote cooperation across their boundaries (Fenema, Keers, \& Zijim, 2014). With a standardized system such as SAP and Oracle, these shared service centres increase intra-organizational efficiencies as the business units are serviced by a common centre. SSC supports in business-to-consumer services such as orders processing, logistics arrangement, call centres, finance, supply chain management and the list go down. Some shared service centres are also involved in business-to-business services in HR, maintenance and R\&D. SSC offers an integrated service module that improves operational efficiency, risk levels, reduces cost, and add values to the stakeholders.

According to a report by MSC Malaysia, there are 405 active global business service companies or SSC in Malaysia (MDEC, 2015). Based on the calculation, it was estimated that 86thousand jobs, to both local and foreign workers were created in this area. Utilizing the geographical and multilingual advantages we have in Malaysia, further emphasis is given by the Government to develop Malaysia into a regional hub for cloud and content services. Currently, some of the pharmaceutical and bio-health companies that had established their SSC in Malaysia include Lilly, Amway, and
1996, 63\% of their health expenditure was recorded on private sector while public health sector had only consisted of $21 \%$.

In Malaysia, approximately $\$ 52$ million was spent by the Government on drug purchases in year 1995 (Babar \& Izham, 2009). After 10 years, the amount increased to $\$ 235.6$ million in 2005. In 2003, total health expenditure per capita was recorded at \$374 with $3.8 \%$ of GDP was allocated to health expenses. The pharmaceutical industry in Malaysia mainly focuses on formulation development and licensed manufacturing from multinational pharmaceutical companies. According to a report in 2004 by Malaysian Ministry of Health, a total of 5750 employees were hired in the local pharmaceutical industry, exporting drugs worth of $\$ 128$ million to over 30 countries. In year 2005, Malaysia pharmaceutical market was valued at $\$ 350.7$ million where $25 \%$ was exported (Babar \& Izham, 2009).

AstraZeneca. The latest SSC launching in Malaysia was made by Roche in year 2016. Malaysia is the first ASEAN country selected by Roche to operate their Global Shared Service Centre which will servicing 15 affiliates across Asia Pacific region (MIDA, 2016).

\subsection{Research Problem}

According to Hefner, the customer experience is managed in 3 stages; Customer Information Points, Customer Point of Sale and Customer Service Points (Hefner, Eva-Maria, Mit , 2010). It starts before the purchase, where information on the drugs is obtained from advertisement or sales promotion. It then continues to during the point of sales; both online and offline. Finally, it is the after-sales-service by the customer care (Scherpen, Draghici, Niemann, 2018). Product and service quality provided by the pharmaceutical during these 3 stages affects customers' satisfaction towards the brand. Among the 10 dimensions of service quality developed by Parasuraman (1985), reliability, responsiveness, communication, credibility and courtesy are some of the key dimensions measured (Farooq, Salam, Fayoll, Jaafar, 2018). A long-term successful customer management requires the pharmaceutical firms to acknowledge any privacy and trust issue, and impact of consumer privacy exploitation towards their brand image (NguyenBang, 2012)

With patients' health record, drug purchase history, pharmacy wholesalers' purchase record and other customer information being handled and processed by a third party system or third party vendor, it brings up the concern about ethics and compliances in handling this sensitive information. Digitalization brought challenges (Scherpen, Draghici, Niemann, 2018) to pharmaceutical industry because now pharmacy wholesalers (direct customers of pharmaceutical companies) maintain their account and purchase online, 
while the appointed third party vendors manage the orders, account and finance information, supply chain management and other transactions through their system.

In Sweden healthcare industry, a shared Electronic Medical Record (EMR) is used to improve communication between patients or consumers with primary and secondary medical care providers. Based on the focus group discussion done by Tully and his team on EMR (Tully, et al., 2013), since the patients' data is created by several doctors and pharmacist, and then shared in the electronics system, it is easily accessed by all. Explicit consent is supposed to be obtained from the patients before viewing this sensitive information. However, most participants in the discussion group admitted that consent is only obtained occasionally (Tully, et al., 2013).

As a highly regulated industry, pharmaceutical companies are always bind to compliances and regulations. Unethical way of handling company sensitive data and customers' private information will lead to serious legal penalties and jeopardize the image of the pharmaceutical company. In 2014, the cost to create and bring a new medicine to market, from starting with a concept, experiments, $R \& D$, to have it market to the public, is approximately USD $\$ 2.6$ billion (Pilon \& Elias, 2015). New medicine molecule data, technology-based reports, experiments records and the like are intellectual property (IP) to pharmaceutical firms (Ghauri \& Rao, 2009). If this IP is disclosed or stolen, the effort and resources poured in by the company will be wasted. Also, advising incorrect information about the drug and promoting an off-label indication which is not approved in the country is a serious offense. Products and services produced by pharmaceutical companies is matter of life and death to their consumers. Hence, integrity is a mandatory value in healthcare industry, no matter which stage in their value chain.

Below are some of the data mishandling cases happened and the negative impact towards pharmaceutical industry.

Brand reliability and credibility is crucial in pharmaceutical industry and ethical customer management begins even before the sales and consumption. During the Customer Information Points (Scherpen, Draghici, Niemann, 2018), only correct and approved information should be advertised and promoted to the public. Drug makers face risk in customer retention (Farooq, Salam, Fayoll, Jaafar, 2018) if the trust and confidence on the brands is no longer exist.

In 2012, the British pharmaceutical company GlaxoSmithKline (GSK) was reported to plead guilty and paid $\$ 3$ billion penalty for promoting their bestselling antidepressants for unapproved off-label indications and failing to report safety data about a top diabetes drug. The agreement also included civil penalties for improper marketing of a half-dozen other drugs manufactured by GSK. It was one of the largest settlements ever happened in pharmaceutical industry (The New York Times, 2012).

Another billion-dollar lawsuit was reported happened to Pfizer in 2009 for $\$ 2.3$ billion when the drug-maker promoted some of their drugs for off-labelled usages which was not approved by Food and Drug Administration (FDA) (Forbes, 2009).

In 2012, Emory Healthcare Inc. in Georgia reported that some computers and mobile devices containing patient social security numbers for about 315,000 surgical patients were stolen (Thomson, 2017). In 2015, there were 253 healthcare data breach cases reported to affect more than 500 individuals and the combined loss is estimated to be over of 112 million records. These were either lost, stolen or inappropriately disclosed (Forbes, 2015) (The New York Times, 2015).

In New Jersey, a former IT administrator in Medco Health Solutions was caught in 2005 for installing a 'logic bomb' in the company computers before being fired. It was a program code that could have erased critical prescription information for 60 million Americans. He was arrested after the programming code was discovered by another IT analyst. According to Christopher J. Christie, the United States attorney for New Jersey in a statement, "A malicious program like this can bring a company's operations to a grinding halt and cause millions of dollars in damage from lost data, system downtime, recovery and repair." (The New York Times, 2006)

US states filed a lawsuit against Bristol-Myers Squibb in year 2002 for fraudulent patent application and numerous frivolous lawsuits in order to prevent lowprice generic of their best-seller cancer drug; Taxol from entering US market (McCarthy, 2002). The pharmaceutical giant was reported to earn nearly $\$ 1$ billion in revenues in year 2000 from the sales of Taxol, before the generic drug.

\subsection{Research Question}

What are the ethical customer management on Organizational Sustainability in pharmaceutical industry in Malaysia?

\subsection{Research Significance}

Over the years, data mishandling in pharmaceutical industry has been constantly reported and each cost billions dollars of settlement. For a more serious scenario, this mishandling might cause a live of a human being. In the case of GSK off-label lawsuit, the company was penalized back in 2004 for another similar case. According to Eliot Spitzer, the New York's attorney general, who sued GlaxoSmithKline in 
2004 over similar accusations involving a different drug, "What we're learning is that money doesn't deter corporate malfeasance". She added that, "The only thing that will work in my view is C.E.O.'s and officials being forced to resign and individual culpability being enforced" (The New York Times, 2012). Company cultures and policies play an important role in making sure all employees in the industry are aware of their responsibilities.

The findings of this study is to provide a guideline to pharmaceutical customer service agents in Malaysia SSCs by emphasizing the importance of ethical customer management and its impact to organization sustainability. This study is also to highlight the importance of management's roles and responsibilities in customer management of pharmaceutical industry operating in Malaysia.

It emphasizes the importance of ethics and compliances in pharmaceutical industry. It is important for management to acknowledge how violation of compliance affects the sustainability of their organization. Ethics and compliance should be the priority in shaping the organization culture and company values. By instilling ethical values and implementing appropriate controls to ensure company operation is compliance-always, it creates a high compliance and integrity-based working environment in the organizations. All employees should be trained and educated on the meaning of customer management ethics, how does it affect the patients and shareholders, and what are the impacts towards the brand and company sustainability.

Next, the finding of this research aims to serve as a reference for future studies on pharmaceutical organization ethics and sustainability issues. Pharmaceutical products are more than just ordinary commercial goods aimed for profit; it is life and death related. With technologies evolving every day, patients' information management is becoming more advance but at the same time, exposed more to security and privacy risk. Hence, researches on ethical customer management is essential to study and develop a customer management system that ensure the patients' welfare and rights are protected. It is also targeted that more efficient ethical customer management theories can be developed and updated, and to be implemented in pharmaceutical industry for the organizational sustainability.

\section{LITERATURE REVIEW}

\subsection{Development of Pharmaceutical Industry}

History written shows that human started to make medicine from plants, animals, or minerals during the early Chinese, Hindu, and Mediterranean civilizations (DaileyJohn, 2016). In 1928, the first antibiotic; penicillin was discovered by Alexander Fleming in London. It had successfully reduced a great number of death from infection. Before the discovery of penicillin, hospitals did not have effective treatments for patients with blood poisoning, infections of pneumonia and rheumatic fever (The Alenxander Fleming Labortory Museum, London, UK, 1999).

After the discovery in 1928, a research team from Oxford University continued to develop Fleming's idea with a serial of animal experiments and clinical trials. After much research and testing, they managed to produce penicillin into a life-saving drug. The Oxford lab was turned into an antibiotic factory where the drug production was carried out (The Alenxander Fleming Labortory Museum, London, UK, 1999). However, it was a difficult time for them in United Kingdom due to the war time condition back in 1940s. The Oxford team travelled to United States in 1941 and they collaborated with Yale physiologists where they continued to develop and improve penicillin production.

In United States, pharmaceutical and chemical companies such as Merck, Pfizer, Squibb and other companies took part in the development of penicillin where they were facing challenges to scale-up the production. By the time, penicillin was a life-saving treatment of various infections in treating the military during war. With the effort from universities, pharmaceutical and chemical companies, new technologies were invented and penicillin production increased dramatically since early 1944 . The drug production in United States increased from 1,663 billion units in 1944, to 133,229 billion units by 1949 . Thanks to the technologies, penicillin price had decreased from 20 dollars per 100,000 units in 1943, to less than 10 cents by 1949 (The Alenxander Fleming Labortory Museum, London, UK, 1999).

Over the years, we witnessed various diseases outbreaks such as SARS and H1N1. Some of these viruses evolved and changed over the time. Hence, pharmaceutical is one of the fast developing and most innovative industries to cure diseases and maintain our health. Pharmaceutical companies continuously develop better vaccines and discover new treatments for chronic illness such as cancers, heart disease, and diabetes. Due to change of lifestyle in this globalization era, mental health issues is the new focus nowadays. Pharmaceutical companies like Lilly and Pfizer continuously developing medicines to treat depression, anxiety disorder, schizophrenia and so on.

Pharmaceutical industry is about improving living quality and saving lives. Since their products are crucial to patients, every single process in the pharmaceutical industry must be controlled and monitored strictly and aligned with ethics and compliances. Pharmaceutical markets are complex in many aspects. It involves rules and regulation, government policies and market demand in different 
countries and regions of the world (A CBO Study, 2006).

Based on study done by National Science Foundation (NSF), pharmaceuticals in United States invested up to USD 5.5billion in research and development of medicine back in year 1980. The amount had then increased tremendously to USD 17billion in 2003 (A CBO Study, 2006). For an innovative new drug, it takes average USD 800million of cost and average 12 years of time to discover, experiment, research and develop a drug molecule that might save millions of precious lives. The cost of research and development has increased in recent years as big pharmaceutical companies are seen to shift their focus to more chronic and degenerative diseases (A CBO Study, 2006).

With such expensive cost and huge impact to the patients, ethics and compliance is important. Violation in any process of the value chain will definitely bring severe and expensive consequences for a pharmaceutical company.

\subsection{Organizational Sustainability}

With the rapid technology invention and development, globalization is accelerating. Obvious changes can be observed in how corporates nowadays are operating their economic, social and environmental processes (Dahl, 2012). In order to survive the rapid changes, organizations now focus on policies to sustain their business. Several indicators were designed internationally for measuring and reporting, mainly emphasized on environmental issue and sustainable development. The current environmental indicators include Environmental Vulnerability Index, Environmental Sustainability Index and Ecological Footprint (Dahl, 2012). Publish of annual environmental information was made mandatory for some European countries like Denmark and Norway (Moore \& Julie, 2008).

In healthcare and pharmaceutical industry, organization is sustainable when the development meets the present needs without affecting the capability of next generation to meet their own needs (Jamaludin, Habidin, Shazali, Ali, \& Khaidir, 2013). Besides legislative and stakeholder pressure (Moore \& Julie, 2008), pharmaceutical industry is a more sensitive industry because its products are to improving life quality and saving human life. Hence, in order for a pharmaceutical firm to stay sustainable in the market, ethics is indeed an important element in their daily operation. Appropriate sustainability indicators on ethical operation guide and assist the pharmaceutical firm to stay competitive in the market and to be able to continuously play their noble roles to human life quality.

In a study done by Moore and Julie, majority companies admitted that their sustainability reporting was conducted due to external drivers; pressure by the legislation and stakeholders (Moore \& Julie, 2008). Some European countries like Denmark, Norway and France even mandate the publishing of corporate environment report annually. There are urge from the public that instead of economic goals, corporates should put more focus on social and environmental goals. During the 2002 World Summit on Sustainable Development held in Johannesburg, importance of ethics in sustainable development was emphasized again by United Nations (Dahl, 2012). For the past years, United Nations have launched several programs such as the Decade of Education for Sustainable Development (2005-2014) and indicators as an effort towards sustainable development. However, there are worries that these indicators and programs are still not enough to change government decision-making and cooperates' behavior (Dahl, 2012).

Sustainability indicators are designed to serve as a powerful tool and solid base for management in decision-making with below five main purposes (Waas, et al., 2014). First of all, it provides structured meaningful information and data to management in decision-making. Next, it operationalizes sustainable development and provides clear and solid guidelines. Thirdly, sustainbility indicators educate and facilitate social learning by changing the society mindset in making decisions. Also, the indicators can be utilized to potrait the firms' accountability and transparency to the public. Lastly, it identifies any knowledge and data gaps and proposes priorities for firms to tackle these gaps internally and externally (Waas, et al., 2014). Sustainability serves an indicator in decicion-make strategy to ensure the rational process connects stakeholders' interest with company values, ideology, knowledge and experience, considering various socioenvironmental contexts.

The International Association for Impact Asssessment defines impact assessment as a process taken by organizations to identify future consequences of a current or proposed action (Waas, et al., 2014). Sustainability assessment is widely used for environmental impact assessment, strategic environmental assessment, health impact assessment and risk assessment. Objectives of these assessments include providing a better interpretation and understanding on sustainability in multi-criteria, and enhance the data management transparency. It is also a information structuring and supporting tools in decision-making process to avoid any irreversible risks, ensure effective communications, be responsive to changes and uncertainties. Sustainability assessment encourages sustainability objectives in organizations with broad participation from all stakeholders and experts, and stimulates continuous learning and process improvement (Waas, et al., 2014).

Based on World Health Organization definition about sustainability, doing the right things now lead the organization to a long-term value creation that benefit 
the consumers and organization. Sustainability in pharmaceutical industry involves developing economic growth through research and innovation to achieving competitive advantages, at the same time sustaining corporate reputation, customer relationships, products and services quality (Shen, Tam, Tam, Ji, 2010) (Szekely \& Knirsch, 2005). Pharmaceutical companies like Bristol-Myers Squibb define and pledge sustainability in conducting their business by contributing to economic growth, social responsibilities and a healthy environment, besides curing serious diseases in patients (Min, DesmoulinsLebeaultFrancois , EspositoMark , 2017). In Baxter, sustainability is long-term approach to include social, economic and environmental responsibilities among their business priorities. Nova Nordisk is also aligned with the sustainability concept where they believed that fundamental to a long-term business achievement is a healthy economy, environment and society (Min , Desmoulins-LebeaultFrancois , EspositoMark , 2017).

\subsection{Ethical Customer Management}

Since pharmaceutical is a highly regulated industry, ethics and compliances are essential to ensure correct products with the accurate information are delivered to the patients, and directly sustain the business. DPOBE Model for Organizational Sustainability (Santos, Anunciação, \& Svirina, 2013) is utilized to measure pharmaceutical organizational sustainability. There are 5 dimensions or pillars emphasized in this model; Direction, Posture, Organization, Behavior and Environment. These dimensions fit perfectly in determining sustainability for pharmaceutical industry.

\section{Direction}

The $1^{\text {st }}$ pillar in DPOBE model is Direction. A corporation's sustainability and long-run prosperity are heavily related to welfare of various stakeholders which inclusive of employees, suppliers and customers (Min , Desmoulins-LebeaultFrancois , EspositoMark , 2017). It is not limited only to stakeholder groups who own stake or have claim on the firms. To gain sustainability through ethical customer management, it starts from its mission and vision, what does management facilitate and consider as a permanent way to run the business (Santos, Anunciação, \& Svirina, 2013).

Four levels of possible industrial design into sustainability are identified as environmental redesign, new and sustainable products and services, new production-consumption systems with sustainable satisfaction of need and desires, and lastly, creating new scenarios for sustainable lifestyles (Küçüksayraç, 2015). Pharmaceutical company strategies generally are adopted and designed to achieve sustainability through corporate initiatives based on external drivers; government regulations and market demand, and internal drivers; creating opportunities for product innovation and improve product quality (Küçüksayraç, 2015).

Johnson \& Johnson is committed to their social contract obligations and uphold ethical values towards the communities with sustainability practices (Turcsanyi \& Sisaye, 2013). Eli Lilly committed to 'make medicines that help people live longer, healthier, more active lives', 'make a significant contribution to humanity' with their core values; integrity, excellence and respect for people (Eli Lilly, 2017). Ethical customer management is a manner where pharmaceutical firms handle their operation to positively impact the society, building positive reputation and gaining trust from their customers (Min Desmoulins-LebeaultFrancois , EspositoMark , 2017).

According to Lega's study, leadership's characteristic and involvement contribute to organizational culture, values and goals. The company culture and strategy depend on management's decision and priority. Managers can motivate the ethical values (Lega, Prenestini, \& Spurgeon, 2013) and continuously building the awareness of these values as an important aspect toward sustainability (Dahl, 2012). Strategy and effort of a pharmaceutical firm on sustainability can also be determined by hiring and retaining high-quality staffs who aligned with the company mission and vision in ethical customer management (Turcsanyi \& Sisaye, 2013).

\section{Posture}

The Posture aspect measures the customer service agents' understanding on the business process, their roles and responsibilities. It is importance for the customer service agents to understand the protocol; a set of rules that govern the interaction of concurrent processes in distribution systems, in every business process they deal with every day (Huang, Huang, Chen , 2009). In the study by Huang and the team, order management protocol modules are classified into four categories; order, response, confirmation and others. It emphasized the appropriate handling of order information to ensure accuracy in order processing, proper response manner, efficient communication with both upstream suppliers and customers, and other transaction carried out daily or on ad-hoc basis.

Daily operation in pharmaceutical SSC also includes providing customer services via call center, helpdesk portals and emails (Harritz , 2016), for any inquiries and complaints. In the 2nd pillar, Posture, we are measuring the ethical principles and conduct codes implemented to the processes (Code of Conduct, 2017) (Esteves, Santos , \& Anunciacao, 2012). This is important to ensure the sensitive and confidential information is handled in a proper manner without violating any regulation. It contributes positive impact towards the organizations accountability and reliability, and customers feel their privacy is respected (Santos, Anunciação, \& Svirina, 2013). 
According to the Code of Conduct by Malaysia Pharmaceutical Society, an unqualified practitioner shall not engage himself publicly in the running of the business of a body corporate in such a manner as to throw doubt upon the status of the superintendent or other pharmacists in such body corporate (Code of Conduct, 2017). Hence, for any inquiry or complaint related to product information; indication, dosage and etc. should be redirected to a qualified person in charge or escalated to Quality personnel of the pharmaceutical firms. If the agent is not confident in handling certain inquiry, he should consult with qualified personnel in the organization before making high-risk decisions which might endanger the patient's life and affect company reputation (Strategic Direction, 2010). Longterm high performances and sustainability depend on both internal and external relationship building which should base on trust, transparency (Benn , Dunphy , \& Griffiths , 2006) and integrity.

Drug safety is a serious issue in pharmaceutical industry and 114 cases were identified in 2005 (Sillup \& Porth, 2008). Based on research by Abud-Mendoza in 2012, an annual cost of USD\$ 1.5 million incurred due to persistence and prevalence of adverse events reported to the Institute of Medicine (Abud-Mendoza , 2012). Adverse events include any informed and uninformed side effects, even death caused by the drug consumption. Since it is a serious matter, all pharmaceutical CS agents should be aware of the procedure in handling such complaints and inquiries.

\section{Organization}

In pharmaceutical Shared Service Center (SSC) or the new term used in Malaysia; Global Business Services (GBS), there is no direct physical interaction with the customers. Customer service agents liaise with the customers; patients, consumers and pharmacies via online retail environment and call centers (Perepelkin \& Zhang , 2011). In this context, trust and brand reputation is one of the key elements to build long-term successful customer relationship. Corporate brand personality that promotes integrity and ethics is a powerful corporate competitive advantage to ensure organization sustainability in pharmaceutical industry.

Comprehensive and clear boundaries is to be defined in the goals of reaching sustainability objectives in pharmaceutical organization (Fenema, Keers, \& Zijim, 2014). This includes clear segregation of roles and responsibilities in GBS especially in Information System Management. All intellectual properties and customer information is collected and stored in cloud platform. Since data is one of the most valuable assets in a firm, effective enterprise customer management system allows coordination and integration of useful data from different channel sources, and enhance the customer experiences (NguyenBang, 2012). Access into different types of information is to be controlled according to the 'right' and 'authority'. It is to protect and ensure sensitive data from mishandling and unintentional data disclosure. If there is information and data to be shared with external business partner, a controlled private cloud should be operated and access opened solely to authorized personnel in the business partners (Laudon \& Laudon, 2016).

Pharmaceutical MNC like Johnson \& Johnson and Lilly pledged to conduct their business in the most noble and highest values. This business policy or strategy is to be clearly conveyed and adapted across all subsidiaries and global business service centers (Kidger , 2002). High quality customer relationship management in pharmaceutical contributes to high customer satisfaction. As part of the knowledge management system, intellectual capital such as knowledge, information, best practices based on previous experiences should be utilized by the local GBS to create competitive advantage (Mehralian , Nazari, Akhavan, \& Rasekh, 2014). Healthcare regulation might differ in different countries and all business partners should be trained to comply with the headquarter mission and vision. Hence, knowledge transfer in MNC should be multidirectional to benefit headquarter, subsidiaries and all business partners such as local logistic service providers (Kidger, 2002).

Managers should implement a proper method to boost IC within the customer service department by providing complete training and education to strengthen employees' professional knowledge and skills. Employees learn to appreciate ethical customer management and ethics code of conduct if they are trained on the logic and impact towards organizational sustainability (Kidger, 2002).

\section{Behavior}

Sustainability in pharmaceutical firms is strongly connected with the organization quality control in industry value chain; both primary and support activities (Laudon \& Laudon, 2016). Erturgut and Soysekerci defined Total Quality Management as an approach organizations used to meet customers' requirement and expectations, by implementing Quantitative methods on the organizational processes, service and products to sustain product development (Erturgut \& Soysekerci , 2009). This measures all activities to insure service quality with strict quality control on efficiency and effectiveness (Ritchter \& Bruhl , 2017). Performance risk and error is to be monitored and minimized through output and behavior control. In pharmaceutical customer management, it requires agents to be aware of the sensitivity of customer information, accuracy and timeliness in order processing to ensure customers receive the drug delivery in time with correct products and quantity (Santos, Anunciação, \& Svirina, 2013). 
Under Johnson \& Johnson policy, customers are protected by the firm's accountability to produce highquality drugs and if there is any issue where the quality is compromised, product recall will be carried out and Johnson \& Johnson committed to their best to rectify the issues (Turcsanyi \& Sisaye, 2013). Such actions from Johnson \& Johnson encourages the customers to have confident, knowing that the firm will always act ethically contribute a positive impact towards their financial performance. Professional and ethical employee behavior; integrity, accountability and honesty allows the firm the manage their reputation and building a healthy and positive customer relationship system based on trust and loyalty, that in return enhance organizational sustainability in this competitive and fast changing industry.

Effective and efficient implementation of operational customer management, especially in IT-related processing enables a pharmaceutical firm focus on analytical customer management, strategic planning on building positive customer relationship, generate customer value and enhance shareholder value for the firm (NguyenBang, 2012). It gives confidence to the customers, and as trust increases commitment and encourages customers to invest in a long-term relationships with the pharmaceutical company.

\section{Evaluation}

Corporate Social Responsibility (CSR) is a concept on how the business activities are carried out continuously in terms of social value; ethically, responsibly and transparently. Pharmaceutical industry is growing their interest in CSR reporting disclosure. Based on a report done by KPMG in 2011 (one of the Big Four accounting firms) on the 100 largest pharmaceutical companies in 34 countries, CSR reporting has obviously doubled since their last survey in 2008 (Azim \& Azam , 2013). In a study on managerial perception of 100 companies in Malaysia, aspect on products and services to customers was actively reported in their social reporting. According to Azim and Azam, one of the major reasons on CSR reporting are corporate accountability to the society and in turn, sustain the company development.

Building awareness of these social values improves corporate image and reputation. A multilevel sustainability indicator is a supporting tool towards organizational sustainability (DahlLyon, 2012). Key performance Indicator (KPI) is implemented in the customer service agents to measure the order processing accuracy and timeliness. It is a standard to ensure customers' requirement on the drug purchases are managed and processed correctly and without delay. Besides individual monitoring, Executive Support System (ESS) such as performances metrics and governance system (FenemaPaul, KeersBianca, ZijimHenk, 2014) within the customer service department allows management to analyze department's performances and evaluate customer satisfaction level (LaudonKenneth \& LaudonJane P., 2016). Based on the data generated, it assists management to identify any ethical gap or under satisfaction in customer management and work out on solutions to overcome this gap immediately. Customer satisfaction is a concept where the business must satisfy its customers in ensuring a long-term relationship, which contribute in the business sustainability and profitability (Farooq, Salam, Fayoll, Jaafar, 2018).

It is also highly recommended that pharmaceutical companies obtain external review on their performances and control system. European and United States companies obtained external review from appointed auditors annually to analyze and evaluate the organization performances and strategies (MooreSharon \& JulieJie Wen , 2008). Both internal and external audit serve as a measurement tools for Malaysia pharmaceutical SSC to evaluate performances and monitor the organizational efficiency and effectiveness (SantosJoão, AnunciaçãoPedro Fernandes , SvirinaAnna, 2013).

\subsection{Conceptual Framework}

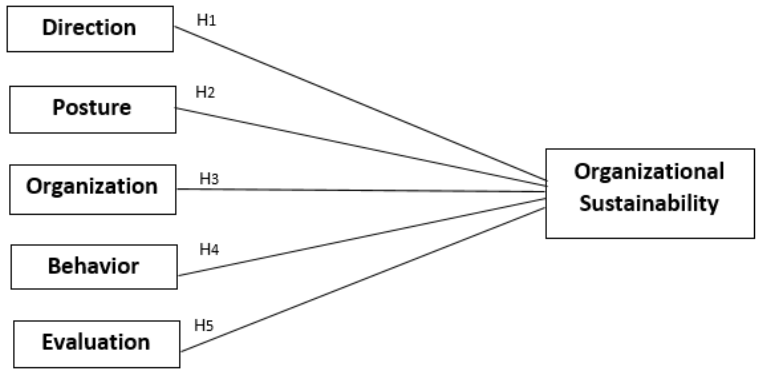

Figure 1: Conceptual framework of the research

These conceptual framework portraits the factors of organizational sustainability in Malaysia pharmaceutical industry. There is a positive impact of company Direction, Posture, Organization, Behavior and Evaluation system towards the organizational sustainability.

\subsection{Theoretical Framework}

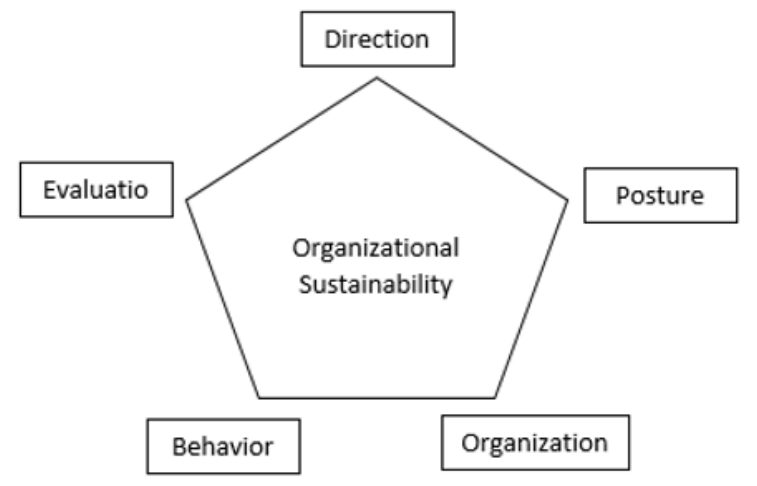


Figure 2: DPOBE Model [Source: Santos et al. (2012) ; López et al. (2010, 2011)]

In this research, level of sustainability in pharmaceutical organization is examined and measured with the implementation of ethical customer management in 'DPOBE Model for Organizational Sustainability '. DPOBE was introduced by Gisbert Lopez and his team in 2010 and is used by some major firms in Portugal to identify major question about sustainability in the organizations (Santos, Anunciação, \& Svirina, 2013). Five pillars were identified in this model as the most important frames in organizational sustainability; Direction, Posture, Organization, Behavior and Evaluation. The five pillars analyzed and explained on how stragetic level, operational level, top management level and activitity reporting level play their roles and responsibilties to maintain and sustain the business.

In this research, level of sustainability in pharmaceutical organization is examined and measured with the implementation of ethical customer management in 'DPOBE Model for Organizational Sustainability '. DPOBE was introduced by Gisbert Lopez and his team in 2010 and is used by some major firms in Portugal to identify major question about sustainability in the organizations (Santos, Anunciação, \& Svirina, 2013). Five pillars were identified in this model as the most important frames in organizational sustainability; Direction, Posture, Organization, Behavior and Evaluation. The five pillars analyzed and explained on how stragetic level, operational level, top management level and activitity reporting level play their roles and responsibilties to maintain and sustain the business.

Organizational sustainability in a pharmaceutical company relies closely to the company culture that emphasizes on ethics, control and compliance. In this research, effective implementation of the 5 aspects; Direction, Posture, Organization, Behavior and Evaluation in managing customer service and relationship contributes to the firm sustainability. It starts from the top where integrity and ethics are set as priority and core culture of the pharmaceutical organization, ethical values instilled in trainings, operations are carried out under code of conduct, accountability in daily interaction with the patients, and finally concludes with a systematic governance system that ensure the pharmaceutical firms to sustain in the industry. It is crucial to maintain the confidence in consumers or patients, where they entrust their lives or lives of their loved ones to a pharmaceutical company. This is only possible when a pharmaceutical firm show strong integrity, accountability and respecting the privacy and putting patients' lives as their priority.

\section{Conclusion \& Implication}

The relationship between organizational sustainability in Malaysia pharmaceutical industry ethical customer management is studied by implementing in DPOBE model. Based on literature review conducted on sustainability and pharmaceutical industry, ethical customer management is only possible when the company has strong sense on compliance and understand the impact of their business processes towards the life quality of their consumers. Ethical code of conduct and integrity is essential in every customer service agent to ensure high quality of service to their customers and to protect the customers' privacy. Organizational culture, systematic knowledge management system and information system ensure CS agents are equipped and well prepared to handle sensitive information from the customers. Organizations that strike for high service quality will make sure their customers get efficient and effective services from the CS agents. And lastly, organizational sustainability also depends on KPI, multidimensional indicator and audit to be put in place as evaluation and measurement tools.

With more pharmaceutical multinational corporations investing in Malaysia for global business services, it is important that the ethical customer management policy is implemented and emphasized locally. Mishandling of customers' sensitive information can be a very serious offence and it might jeopardize the reputation of the pharmaceutical company. In a more severe situation, a patient's life quality will be affected. Comprehensive conduct code and guidelines to the local global business services is mandatory to maintain the service quality and sustain the pharmaceutical shared service centers industry in Malaysia.

Pharmaceutical industry carries a noble responsibility to improve human life quality. As highlighted in literature review, it is believed that ethical customer management in customer service contributes to positive brand image and eventually leads to organizational sustainability.

\section{Reference}

A CBO Study. (2006). Research and Development in the Pharmaceutical Industry. The Congress of the United States.

Abud-Mendoza , C. (2012). Medical Ethics, Research and the Pharmaceutical Industry. Reumatol Clin, 233235 .

Azim , M., \& Azam , S. (2013). Corporate

Sustainability Reporting by Pharmaceutical Companies: Is It What It Seems to Be? Corporate Ownership of Control, 11, 754-764. 
Babar, Z., \& Izham, M. (2009). Effect of privatization of the drug distribution system on drug prices in Malaysia. Public Health 123, 523-533.

Benn, S., Dunphy , D., \& Griffiths, A. (2006). Enabling change for corporate sustainability: an integrated perspective. Australian Journal of Environmental Management, 156-165.

Beyond Borders. (2015). In MDEC Global Business Services Division Newsletter.

Bunniran, S., McCaffrey, D., Bentley, J., \& Bouldin , A. (2009). Pharmaceutical product withdrawal: Attributions of blame and its impact on trust. Research in Social and Administrative Pharmacy 5, 262-273.

Chatterjee, C., \& Srinivasan, V. (2013). Ethical issues in health care sector in India. IIMB Management Review, 25, 49-62.

Code of Conduct. (2017). Retrieved May 10, 2017, from Malaysian Pharmaceutical Society: http://www.mps.org.my/index.cfm?\&menuid=57\#TOC

Dahl, L. A. (2012). Achievement and gaps in indicators for sustainability. Ecological Indicators, 17, 14-19.

Dailey, J. W. (2016, May 9). pharmaceutical industry. Retrieved September 27, 2017, from Encyclopædia Britannica:

https://www.britannica.com/topic/pharmaceuticalindustry

Das, A. (2011). Pharmaceutical industry and the market: The case of Prozac and other antidepressants. Asian Journal of Psychatry V4, 14-18.

Eli Lilly. (2017). lillyforbetter.lilly.com. Retrieved June 1,2017

Erturgut, R., \& Soysekerci , S. (2009). The problem of sustainability of organizational success in public educational institutions: a research on the education administrator in Turkey. Procedia Social and Behavioral Sciences, 2092-2102.

Esteves, F., Santos , J., \& Anunciacao, P. (2012). Sustainability in the information society: a proposal of information system requirements in view of the DPOBE model for organizational sustainability. Procedia Technology, 5, 599-606.

Farooq, M., Salam, M., Fayoll, A., \& Jaafar, N. (2018) Impact of service quality on customer satisfaction in
Malaysia airlines: A PLS-SEM approach. Journal of Air Transport Manage, 169-180.

Fenema, P. C., Keers, B., \& Zijim, H. (2014).

Interorganizational Shared Services: Creating Value across Organizational Boundaries. Advanced Series in Management V.13, 175-217.

Forbes. (2009, September 9). Retrieved May 21, 2017, from Pfizer's \$2.3 Billion-Dollar Settlement: https://www.forbes.com/2009/09/08/pfizer-biliondollar-settlement-fda-opinions-contributors-david-rhenderson-charles-1-hooper.html

Forbes. (2015, December 31). Retrieved May 21, 2017, from Data Breaches In Healthcare Total Over 112 Million Records In 2015:

https://www.forbes.com/sites/danmunro/2015/12/31/da ta-breaches-in-healthcare-total-over-112-millionrecords-in-2015/\#382ed72c7b07

Ghauri, P. N., \& Rao, P. (2009). Intellectual property, pharmaceutical MNEs and the developing world . Journal of World Business 44, 206-215.

Hair, J., Babin, B., Money, A., \& Samouel, P. (2007). Essentials of Business Research Methods. USA: John Wiley \& Sons.

Harritz , D. (2016). Role of management devices in enacting strategy - case study of Shared Service Centre. Journal of Accounting \& Organizational Change, 504521.

Hefner, Eva-Maria, \& Mit , d. (2010). Customer Touchpoint Management als Strategie. Marketing Review St. Gallen 27, 27-31.

Huang, C.-Y., Huang, T.-S., \& Chen , W.-L. (2009). Communication protocols for order management in collaborative manufacturing. Int. J. Production Economics, 257-268.

Jamaludin, N. H., Habidin, N. F., Shazali, N. A., Ali, N., \& Khaidir, N. A. (2013). Exploring sustainable healthcare service and sustainable healthcare performance: based on Malaysian healthcare industry. Journal of Sustainable Development Studies, 14-26.

Kenneally, M., \& Valerie, W. (2012). Pharmaceutical Cost-Containment Policies and Sustainability: Recent Irish Experience. Value in Health 15, 389-393. 
Kidger , P. (2002). Management structure in multinational enterprises - responding to globalisation. Employee Relations, 24, 69-85.

Krejcie \& Morgan. (1970). Determining Sample Size for Research Activities. Educational and Psychological Measurement, 607-610.

Küçüksayraç, E. (2015). Design for sustainability in companies: strategies, drivers and needs of Turkey's best performing businesses. Journal of Cleaner Production, 455-465.

Kumar, M., Talib, S., \& Ramayah, T. (2013). Business Research Methods. Companion Website.

Landmarks, A. C. (n.d.). Discovery and Development of Pnicillin. Retrieved September 20, 2017, from International Historic Chemical Landmark: http://www.acs.org/content/acs/en/education/whatische mistry/landmarks/flimingpenicillin.html

Laudon, K. C., \& Laudon, J. (2016). Management Information Systems Managing the Digital Firm. Pearson Education Limited.

Lega, F., Prenestini, A., \& Spurgeon, P. (2013). Is Management Essential to Improving the Performance and Sustainability of Health Care Systems and Organizations? A Systematic Review and a Roadmap for Future Studies. Value in Health, 16, S46-S51.

Linnenluecke, M. K., \& Griffiths, A. (2010). Corporate sustainability and organizational culture. Journal of World Business, 45, 357-366.

Maheswari, U., B., R., Parmata, D., \& B., S. R. (2016). Measuring service quality in pharmaceutical supply chain - distributor's perspective.

McCarthy, M. (2002). US states file lawsuit against Bristol-Myers Squibb. The Lancet V359.

MDEC. (2015). MSC Malaysia Annual Industry Report 2015. MSC Malaysia National ICT Initiative.

Mehralian, G., Nazari, J., Akhavan, P., \& Rasekh, H. (2014). Exploring the relationship between the knowledge creation process and intellectual capital in the pharmaceutical industry. The Learning Organization, 21, 258-273.

MIDA. (2016, October 26). Malaysian Investment Development Authority. Retrieved May 20, 2017, from Malaysian Investment Development Authority: http://www.mida.gov.my/home/3307/news/rocheexpands-footprint-in-malaysia-with-the-opening-ofglobal-shared-service-centre-for-asia-pacific-region-insunway/

Milne, M., \& Gray, R. (n.d.). Prospects For Sustainability Reporting. 184-207.

Min , M., Desmoulins-Lebeault, F., \& Esposito, M. (2017). Should Pharmaceutical companies engage in corporate social responsibility? Journal of Management Development, 36, 58-70.

Moore, S., \& Julie, J. (2008). Business ethics? A global comparative study on corporate sustainability approaches. Social Responsibility Journal, 172-184.

MSC Malaysia. (2017). Global Business Services. Retrieved May 20, 2017, from MSC Malaysia: http://www.mscmalaysia.my/gbs

Nguyen, B. (2012). The dark side of customer relationship management: Exploring the underlying reasons for pitfalls, exploitation and unfairness. Journal of Database Marketing \& Customer Strategy Management, 56-70.

OECD. (2015). Research and development in the pharmaceutical sector. In Health at a Glance 2015 (pp. 188-189). Paris: OECD Publishing.

Perepelkin , J., \& Zhang , D. (2011). Brand personality and customer trust in community pharmacies. International Journal of Pharmaceutical and Healthcare, 5, 175-193.

Peters, S. (2014). Tufts Center for the Study of Drug Development. Retrieved May 21, 2017, from http://csdd.tufts.edu/files/uploads/cost_study_backgrou nder.pdf

Pilon, F., \& Elias, H. (2015). Strategic account management as a value co-creation selling model in the pharmaceutical industry. Journal of Business \& Industrial Marketing.

PMLive. (2017). Retrieved from Top 25 pharma companies by global sales: http://www.pmlive.com/top_pharma_list/global_reven ues

Ritchter , P., \& Bruhl , R. (2017). Shared service center research: a review of the past, present and future. European Management Journal, 35, 26-38. 
Santos, J., Anunciação , P., \& Svirina, A. (2013). A Tool to Measure Organizational Sustainability. Journal of Business Management No.7, 105-117.

Scherpen, F., Draghici, A., \& Niemann, J. (2018). Customer Experience Management to Leverage Customer Loyalty. 14th International Symposium in Management, 374-380.

Sekaran, U., \& Bougie, R. (2010). Business Research Methods. A Skill Building Approach. New York: John Wiley \& Sons Inc. .

Shen, L., Tam, V., Tam, L., \& Ji, Y. (2010). Project feasibility study: the key to successful implementation of sustainable and socially responsible construction management practice. Journal of Cleaner Production, 254-259.

Sillup , G., \& Porth, S. (2008). Ethical issues in the pharmaceutical industry: an analysis of US newspaper. International Journal of Pharmaceutical and Healthcare, 163-182.

Strategic Direction. (2010). Ethics and sustainability in today's business environment - creating new ways of doing business and educating business leaders . Strategic Direction, 12-15.

Szekely, F., \& Knirsch, M. (2005). Responsible leadership and corporate social responsibility: metrics for sustainable performance . European Management Journal , 628-647.

Teerawattananon, Y., Tangcharoensathien, V., Tantivess, S., \& Mills, A. (2003). Health sector regulation in Thailand: recent progress and the future agenda. Health Policy V.63, 323-338.

The Alenxander Fleming Labortory Museum, London, UK. (1999). The Discovery and Development of Penicillin 1928-1945. An International Historic Chemical Landmark.

The Congress of the United States . (2006). Research and Development in the Pharmaceutical Industry. Congressional Budget Office.

The New York Times. (2006, December 20). Retrieved May 21, 2017, from U.S. Says Ex-Worker at Drug Giant Was Out to Damage Computer Data: http://www.nytimes.com/2006/12/20/nyregion/20data. html
The New York Times. (2012, July 2). Retrieved May 21, 2017, from Glaxo Agrees to Pay \$3 Billion in Fraud Settlement :

http://www.nytimes.com/2012/07/03/business/glaxosm ithkline-agrees-to-pay-3-billion-in-fraud-

settlement.html?mcubz=2

The New York Times. (2015, February 2). Retrieved May 21, 2017, from Millions of Anthem Customers Targeted in Cyberattack:

https://www.nytimes.com/2015/02/05/business/hackers -breached-data-of-millions-insurer-

says.html?mcubz=2\&_r=0

The Research Advisors. (2006). Sample Size Table. Retrieved June 2, 2017, from The Research Advisors: http://www.researchadvisors.com/tools/SampleSize.htm

Thomson, L. L. (2017). Health Care Data Breaches. In HEALTH CARE DATA BREACHES AND INFORMATION SECURITY (pp. 254-267).

Tully, M. P., Kettis, A., Hoglund, A., Morlin, C., Schwan, A., \& Ljungberg, C. (2013). Transfer of data or re-creation of knowledge - Experience of a shared electronic patient medical records system.

Turcsanyi, J., \& Sisaye, S. (2013). Corporate social responsibility and its link to financial performance Application to Johnson \& Johnson, a pharmaceutical company. World Journal of Science Technology and Sustainable Development, 4-19.

U.S. Department of Commerce. (2016). 2016 Top Markets Report Pharmaceuticals. International Trade Administration.

United States Food \& Drug Administration. (2017).

Retrieved June 4, 2017, from Development \& Approval Process (Drugs):

https://www.fda.gov/drugs/developmentapprovalproces s/

University of the West of England. (2018). Pearson's Correlation Coefficient. Retrieved from http://learntech.uwe.ac.uk/da/Default.aspx?pageid=144 2

Waas, T., Hugé, J., Block, T., Wright, T., BenitezCapistros, F., \& Verbruggen, A. (2014). Sustainability Assessment and Indicators: Tools in a DecisionMaking Strategy for Sustainable Development. Sustainability, 5512-5534. 
Yeoh, P.-L. (1994). Speed to Global Markets: An

Empirical Prediction of New Product Success in the

Ethical Pharmaceutical Industry . European Journal of

Marketing, 29-50. 